\title{
Patterns of coronary artery disease in post-infarction ventricular septal rupture
}

\author{
J D SKEHAN, * CATHERINE CAREY, * M S NORRELL, $\dagger$ M DE BELDER, * \\ R BALCON, $\dagger$ P G MILLS *
}

From The London Hospital, Whitechapel and †The London Chest Hospital, London

SUMMARY Cardiac angiography was reviewed in 91 patients with post-infarction ventricular septal rupture. The results were compared with those of 123 stable survivors who had a positive $\tilde{i}^{+}$ submaximal exercise test early after infarction. Anterior infarction and occlusion of the infarct $\infty$ vessel were more common in those with ventricular septal rupture than in the comparison group. In $\bigcirc$ the group with ventricular septal rupture there was more left ventricular damage, with aneurysm formation in two thirds, and coronary angiography showed more single than triple vessel disease. In the comparison group there was more triple vessel disease than single vessel disease. Angiographically demonstrable collaterals to the infarct territory were not seen or only very faintly seen in $82 \%$ of those with septal rupture. Well developed collaterals were seen in two thirds of the comparison group.

These patterns of coronary disease suggest that ventricular septal rupture is more likely in patients with coronary occlusion and little or no collateral support to the infarct territory.

The interventricular septum is believed to rupture in approximately $1 \%$ of survivors of myocardial infarction. ${ }^{1}$ Early investigation and operation are the usual treatment. ${ }^{2-4}$ This study was prompted by the clinical impression that we were seeing consistent patterns of coronary collateral circulation and left ventricular anatomy in patients with post-infarction septal rupture.

It is difficult to find an appropriate control group in an observational study. Differences in patient selection, angiographic assessment, and intervals from infarction to investigation often make comparison with other published trials inappropriate. We overcame some of these problems by using a large well defined consecutive series of stable survivors of infarction as a comparison group. ${ }^{5}$ We selected patients from the London and Newham hospitals who had an early post-infarction exercise test. This was followed by early coronary and left ventricular angiography. So the comparison group showed the angiographic features seen by us soon after infarction and this allowed direct comparison with the features we found in patients with septal rupture.

Requests for reprints to: Dr J D Skehan, Cardiac Department, The London Hospital, Whitechapel, London E1 1BB.

Accepted for publication 2 May 1989

\section{Patients and methods}

\section{PATIENTS}

Ventricular septal rupture after myocardial infarction We included all 91 patients seen from 1979 to 1987 at the London Hospital and London Chest Hospital with post-infarction septal rupture in whom cardiac cineangiograms were available.

\section{Comparison group}

A consecutive series of stable survivors of infarction aged $<65$ years underwent submaximal exercise $\circ$ testing at a mean interval of 12 days after infarction. A positive result was based on ischaemic changes on the electrocardiogram, angina, an abnormal blood pressure response, the development of ventricular $\sigma$ arrhythmias, or inability to complete the protocol. N Left ventricular and coronary angiography was performed on all 123 patients in this comparison group.

\section{ANGIOGRAPHIC STUDY}

Extent of coronary disease

The severity of coronary disease was assessed in at 7 least two, and usually six projections by independent $\overrightarrow{0}$

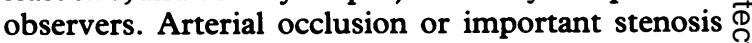
(luminal diameter reduced by $70 \%$ or more) was $\bar{\pi}$ assessed in the infarct and in the non-infarct related vessels. 
Table Characteristics of patients with acquired ventricular septal rupture after myocardial infarction and a comparison group who had a positive submaximal exercise test soon after infarction

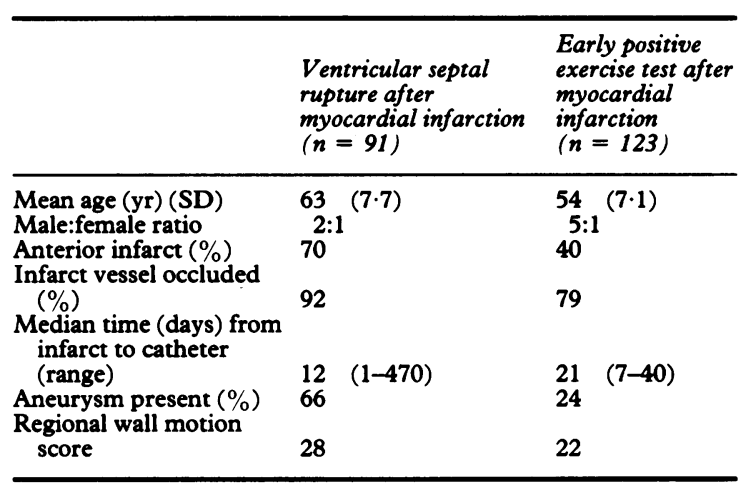

\section{Collateral circulation}

Cross filling collateral circulation to the infarct related artery was assessed by a simple scoring system indicating flow from other vessels, whether dominant or non-dominant: 0 , no collateral circulation; 1 , faint filling of branch vessels; 2 , faint filling of epicardial vessel; 3 , good filling of epicardial vessel.

\section{Left ventricular function}

We used the system adopted by the Coronary Artery Surgery Study investigators to score regional wall motion and so estimate left ventricular function. ${ }^{6}$ The left ventricular angiograms in both right and left anterior oblique projections were divided into five segments and each was scored as follows: 1 , normal contraction; 2 , mild hypokinesia; 3 , severe hypokinesia, 4, akinesia; 5, dyskinesia; 6, aneurysm formation.

The sum of all the segments' scores gives a total left ventricular score. A normal result is 10 and higher scores indicate greater degrees of left ventricular dysfunction. In addition to this numerical scoring system we examined each left ventricular angiogram for an aneurysm, defined as discrete regional systolic expansion.

We used $\chi^{2}$ analysis to compare the angiographic variables of the two study groups.

\section{Results}

\section{CHARACTERISTICS OF GROUPS (TABLE)}

The table shows the differences between the patients with septal rupture and the comparison post-infarction group. Patients with septal rupture were older (63 yr $v 54 \mathrm{yr}$ ), had a more even ratio of men to women (2:1), and a greater preponderance of anterior infarctions $(70 \% v 40 \%)$. The two groups overall had

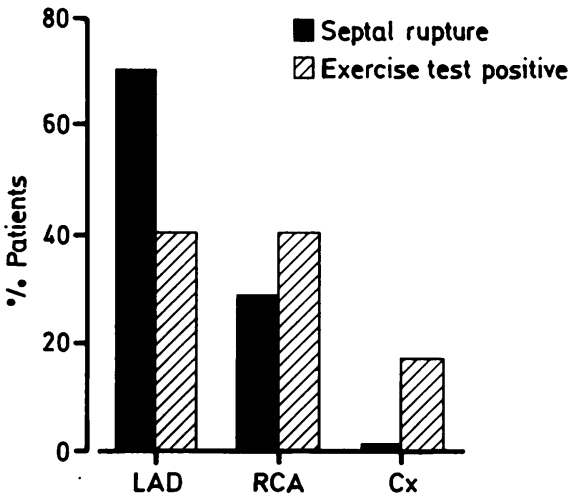

Fig 1 Infarct vessel at angiography in patients with septal rupture and in the comparison group with a positive submaximal exercise test after infarction. $L A D$, left anterior descending coronary artery; $R C A$, right coronary artery; Cx, circumflex.

a similar interval from infarction to angiography, but some patients with septal rupture presented a considerable time after infarction. The longest interval was more than a year. Most patients with septal rupture were investigated within two weeks of infarction and within a few days of the diagnosis of septal rupture (median interval 12 days (range $1-470$ ). The median delay in the comparison group was 21 days (range 7-40) from infarct to angiography.

\section{CORONARY ANGIOGRAPHY (TABLE, FIGS 1}

AND 2)

Anterior infarction was more common in patients with septal rupture and this accorded with the higher rate of occlusion of the left anterior descending artery $(70 \%)$. Total occlusion of the infarct vessel was more common in those with septal rupture than in the

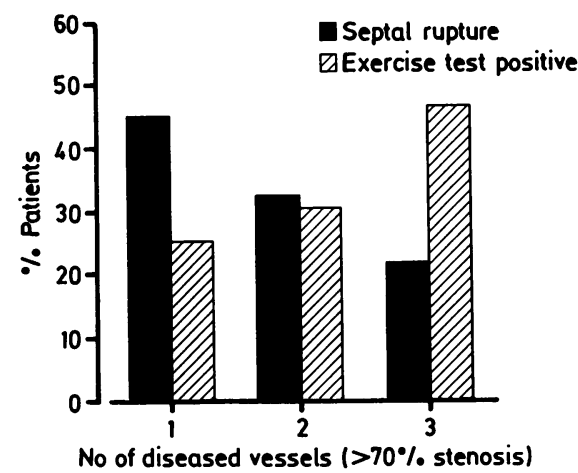

Fig 2 Extent of coronary disease at angiography in patients with septal rupture after myocardial infarction and in a comparison group with a positive submaximal exercise test after myocardial infarction. 


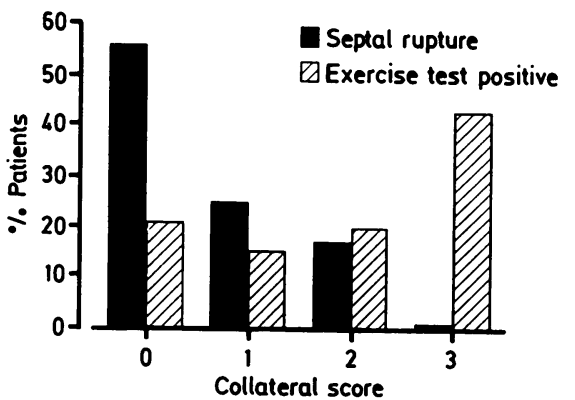

Fig 3 Extent of collateral circulation to the infarct related artery in patients with septal rupture after infarction and in a comparison group with a positive submaximal exercise test after infarction.
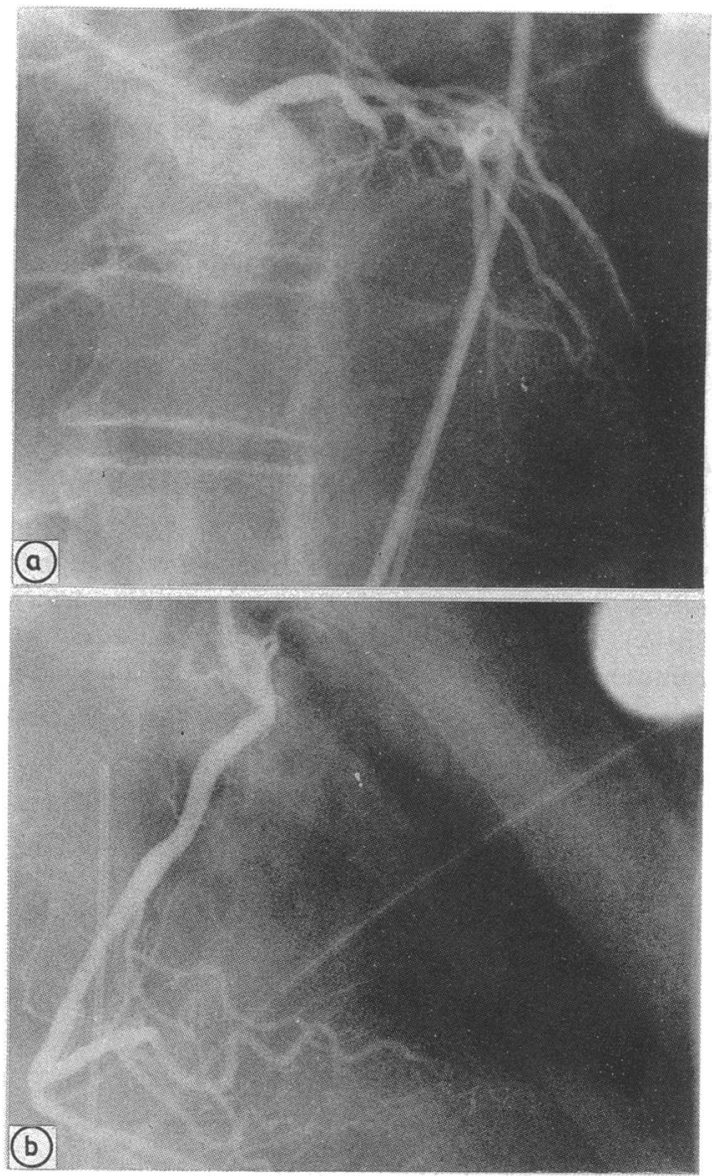

Fig 4 Coronary angiography in a patient after anterior infarction complicated by septal rupture. The left coronary angiogram (a) shows occlusion of the anterior descending branch which has no collateral filling of the distal vessel from the right coronary artery $(b)$.
Skehan, Carey, Norell, de Belder, Balcon, Mills
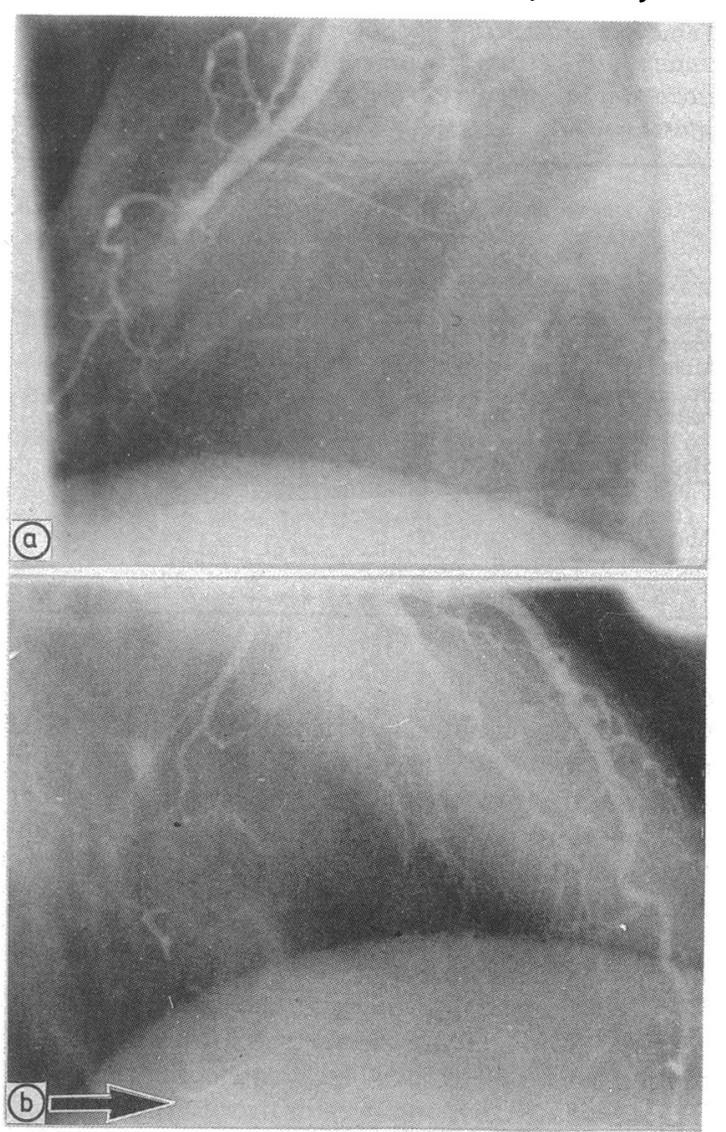

Fig 5 Coronary angiography in a stable patient soon after inferior infarction. The right coronary angiogram $(a)$ is occluded. The left coronary angiogram (b) shows good distal filling of the right coronary artery via collaterals.

comparison group $(92 \% v 79 \%, \mathrm{p}<0.01)$. There was more single vessel disease than triple vessel disease in those with septal rupture (43\% v 24\%). The reverse was true in the comparison group ( $p<$ $0.01)(25 \%$ single vessel disease and $45 \%$ triple vessel disease).

\section{COLLATERAL CIRCULATION TO INFARCT}

RELATED ARTERY (FIGS 3, 4, AND 5)

We found a striking and highly significant difference $(p<0.001)$ in the pattern of collateral circulation to the infarct territory in the two study groups. Over half $(56 \%)$ of the patients with septal rupture had no angiographically demonstrable collaterals and a further $26 \%$ had only faint (grade 1) branch vessel filling. Just one of the 91 patients had a grade 3 collateral supply to the epicardial portion of the infarct related artery. In the comparison group, however, over half had well developed collateral 
circulation with grade $3(45 \%)$ or $2(20 \%)$ scores. Ranking the patients (either group) according to the interval since infarction, age, or site of infarction or degree of left ventricular impairment made no difference to the results of collateral scoring.

\section{LEFT VENTRICULAR ANGIOGRAPHY (TABLE)}

Another clear and statistically significant difference between the study groups was the frequency of aneurysm formation. There was a left ventricular aneurysm in $66 \%$ of the septal rupture group and only $24 \%$ of the comparison group (p $<0.0001)$ and patients with septal rupture showed a greater degree of left ventricular damage as judged by the regional wall motion score. They had a higher mean score than the comparison group $(28 v 22 \mathrm{p}<0.01)$.

\section{Discussion}

This series of 91 patients with post-infarction ventricular septal defect from two referral centres gives a broad clinical experience of this condition. In the past clinical attitudes favoured delayed transfer to referral centres such as our hospitals, and this probably would have led to many of these high risk patients dying before investigation and operation. ${ }^{2}$

In patients with septal rupture there were fewer collaterals to the infarct territory. Our comparison group, chosen because of the short interval from infarction to angiography, had more three vessel disease than those with septal rupture. An earlier report on early angiography in a large unselected consecutive group of survivors of infarction showed a similar pattern of coronary disease to that seen in our patients with ventricular septal defects. ${ }^{7}$ But $61 \%$ had collaterals - a similar proportion to that found in our comparison group. This emphasises the lack of collateral circulation associated with ventricular septal rupture.

Human collateral circulation varies ${ }^{8}$ and its pattern of development is unclear. Coronary collateral vessels are thought to enlarge in the presence of obstructive coronary disease creating a pressure gradient and encouraging flow between the epicardial coronary arteries. ${ }^{9}$ In acute coronary occlusion, collateral circulation may be seen immediately but its functional importance and time course of development are not known in humans. Reports from a series of patients studied after infarction, who had occlusion of the infarct vessel, give some insight to the rate of progression of collaterals. ${ }^{10}$ Just $16 \%$ had collaterals visible on angiography within six hours but after the first day the rate rose to $62 \%$ (grade II-III collateral score) with only small increases in the iollowing weeks. This suggests that the small differences in the intervals from infarction to angiography in our two groups are unlikely to have influenced the results significantly. Sporadic case reports have indicated that a collateral circulation may be well developed in the absence of chronic obstructive disease and protect the heart after ligation of the left anterior descending artery ${ }^{11}$ or traumatic right coronary arteriocameral fistula. ${ }^{12}$ Large retrospective studies of patients with coronary disease have given an indication of the functional importance of collaterals seen on coronary angiography. Evidence from studies of regional wall motion supports the view that collaterals protect the heart when coronary occlusion occurs. ${ }^{1314}$ This effect was of more benefit after occlusion of the left anterior descending artery than after occlusion of the right coronary artery. ${ }^{15}$

Our findings indicate that septal rupture after infarction is most likely to be associated with total occlusion of a coronary artery (usually the left anterior descending artery) with little or no collateral flow to the infarct territory. The absence of collateral flow probably increases regional necrosis leading to an increased risk of left ventricular aneurysmal dilatation and septal rupture. Alternatively, the absence of collateral circulation could simply reflect the extensive myocardial damage. This is unlikely in view of the equal distribution of collaterals in our comparison group irrespective of the extent of left ventricular damage. If our original hypothesis were correct then the pattern of coronary artery disease in patients with rupture of the left ventricular free wall should be similar-data from necropsy studies support this view. ${ }^{16}$ In 20 cases postmortem angiography showed a recent occlusion in a coronary artery with no collateral circulation to the infarct territory.

Doppler echocardiography is a reliable method for the diagnosis of ventricular septal rupture after myocardial infarction and it has been suggested that invasive investigation before operation might be unnecessary. ${ }^{1718}$ Our results show that single vessel disease was more common in patients with septal rupture than in the comparison group. But half of the septal rupture group did have disease in the noninfarct related vessels ( $30 \%$ two vessel disease, $21 \%$ three vessel disease) of sufficient severity to be considered for aortocoronary bypass grafting. Establishing the diagnosis of septal rupture should not now require cardiac catheterisation, but coronary angiography remains a useful preoperative investigation.

This review of patients with septal rupture confirmed our initial clinical impression that most cases occurred in elderly patients with single vessel disease, total occlusion of the infarct vessel, and no collateral support to a large area of infarction. The angiographic appearance was different from that seen in a stable group of patients who were also assessed soon after infarction. 


\section{References}

1 Fox AC, Glassman E, Isom OW. Surgically remedial complications of myocardial infarction. Prog Cardiovasc Dis 1979;21:461-84.

2 Norell MS, Gershlick AH, Pillai R, et al. Ventricular septal rupture complicating myocardial infarction: is earlier surgery justified? Eur Heart $J$ 1987;8:1281-6.

3 Loisance DY, Cachera JP, Poulain H, Aubry PH, Juvin AM, Galey JJ. Ventricular septal defect after acute myocardial infarction. Early repair. $J$ Thorac Cardiovasc Surg 1980;80:61-7.

4 Scanlon PJ, Montoya A, Johnson SA, et al. Urgent surgery for ventricular septal rupture complicating acute myocardial infarction. Circulation 1985;72 (suppl II):185-90.

5 de Belder MA, Pumphrey CW, Skehan JD, et al. Relative power of clinical, exercise test, and angiographic variables in predicting clinical outcome after myocardial infarction: the Newham and Tower Hamlets study. Br Heart $J$ 1988;60:377-89.

6 The National Heart, Lung and Blood Institute Coronary Artery Surgery Study (CASS). The principal investigators of CASS and their associates. Circulation 1981;63(suppl I):1-65.

7 Bosch X, Theroux P, Waters DD, Pellitier GB, Roy D. Early postinfarction ischaemia: clinical, angiographic and prognostic significance. Circulation 1987;75: 988-95.

8 Fulton WFM. The coronary arteries. Springfield, Illinois: Charles C Thomas, 1965:127-8.

9 Blumgart HL, Schlesinger MJ, Zoll PM. Angina pectoris, coronary failure and acute myocardial infarction. The role of coronary occlusions and collateral circulation. JAMA 1941;116:91-7.

10 Lieboff RH, Schwartz H. Clinical sequelae: special patient subsets, incomplete occlusion of the infarctrelated artery and coronary collaterals. Circulation 1987;76(suppl II):115-20.

11 Carleton RA, Boyd T. Traumatic laceration of the left anterior descending artery treated by ligation without myocardial infarction. Report of a case with review of the literature. Am Heart J 1958;56:136-42.

12 Siepser SL, Kaltman AJ, Mills N, Pughkem T, Fox AC. Coronary collateral flow after traumatic fistula between right coronary artery and right atrium. $N$ Engl J Med 1972;287:754-6.

13 Carroll RJ, Verani MS, Falsetti HL. The effect of collateral circulation on segmental left ventricular contraction. Circulation 1974;50:709-13.

14 Kolibash AJ, Bush CA, Wepsic RA, Schroeder DP, Tetalman MR, Lewis RP. Coronary collateral vessels: spectrum of physiologic capabilities with respect to providing rest and stress myocardial perfusion, maintenance of left ventricular function and protection against infarction. Am J Cardiol 1982;50:230-8.

15 Hamby RI, Aintablian A, Schwartz A. Reappraisal of the functional significance of the coronary collateral circulation. Am J Cardiol 1976;38:305-9.

16 Wessler S, Zoll PM, Schlesinger MJ. The pathogenesis of spontaneous cardiac rupture. Circulation 1952;6: 334-51.

17 Cheeseman MG, John R, Murray N, Redding VJ. Pulsed Doppler ultrasound in the diagnosis of postinfarction ventricular septal defect [Abstract]. $\mathrm{Br}$ Heart J 1987;57:563.

18 MacLeod D, Fananapazir L, de Bono D, Bloomfield P. Ventricular septal defect after myocardial infarction: assessment by cross sectional echocardiography with pulsed wave Doppler scanning. Br Heart J 1987;58: 214-7. 